\title{
Are Newer-Generation Drug-Eluting Stents More Effective in Women than Early-Generation Ones?
}

\author{
Andrea Messori1,2*, Valeria Fadda', Dario Maratea1, Sabrina Trippoli1 \\ ${ }^{1}$ HTA Unit, ESTAV Toscana Centro, Regional Health Service, Firenze, Italy \\ ${ }^{2}$ ESTAV Centro, Area Vasta Centro Toscana, Regional Health System, Prato, Italy \\ Email: andrea.messori.it@gmail.com, ${ }^{*}$ andrea.messori@estav-centro.toscana.it
}

Received 26 February 2014; revised 29 March 2014; accepted 6 April 2014

Copyright (C) 2014 by authors and Scientific Research Publishing Inc.

This work is licensed under the Creative Commons Attribution International License (CC BY). http://creativecommons.org/licenses/by/4.0/

(c) (i) Open Access

\begin{abstract}
Evidence-based research is increasingly aimed at differentiating between no proof of difference (failed demonstration of superiority) and proof of no difference (demonstration of equivalence). The latter requires that equivalence margins are incorporated in the analysis of outcomes. We applied an analysis of equivalence to study the incremental benefit of newer-generation vs earlygeneration drug-eluting stents (DES) in women receiving percutaneous coronary intervention. The clinical material was derived from published data. Our equivalence testing was focused on the end-point of target-lesion revascularisation (TLR). Results were expressed as rate differences (RDs), while the equivalence margins $( \pm 2.9 \%)$ were derived from the statistical power calculations of a recent trial. Our results clearly indicated that, in women, there was an equivalent effectiveness between newer-generation and early-generation of DES.
\end{abstract}

\section{Keywords}

Coronary Drug-Eluting Stents, Equivalence, Margins

\section{Introduction}

For more than a decade, drug-eluting stents (DES) have been the mainstay for the treatment of coronary artery disease. Technology advancements of DES have been particularly relevant over the last few years and have resulted in increased safety and efficacy of newer-generation vs early-generation DES, as several randomised trials and meta-analyses have documented [1] [2]. Anyway, the data for safety and efficacy of DES in women are

\footnotetext{
${ }^{*}$ Corresponding author.
}

How to cite this paper: Messori, A., Fadda, V., Maratea, D. and Trippoli, S. (2014) Are Newer-Generation Drug-Eluting Stents More Effective in Women than Early-Generation Ones? World Journal of Cardiovascular Diseases, 4, 146-148. 
sparse because their inclusion in randomised clinical trials is generally limited [1].

On the other hand, recent studies, particularly in the field of pharmacotherapy have addressed the question of whether or not the incremental benefits found in randomized trials are consistent with the expected outcomes that are pre-declared in statistical power calculations of the trials [3] [4]. In particular, a comparison has been proposed between the pre-specified "delta" (or margin) declared in the statistical power section of the trials and the real incremental benefit observed thereafter from the trial's results (or meta-analyses). These margins, that are assumed to identify a threshold between clinically relevant benefits and irrelevant ones, can be handled in the framework of equivalence tests, and equivalence corresponds to demonstrating the proof of no difference.

In this report, we describe the application of this type of analysis for interpreting the incremental benefit of newer-generation vs early-generation DES in women receiving percutaneous coronary intervention.

\section{Methods}

Our clinical material was obtained from the meta-analysis by Stefanini et al. [1] who studied this specific comparison according to the end-point of target-lesion revascularisation (TLR), The crude rates of TLR for newergeneration DES and early-generation DES were, respectively, 236/6278 (3.76\%) vs 205/4171 (4.91\%) at 1 year and 330/6278 (5.26\%) vs 294/4171 (7.05\%) at 3 years. These findings generate a rate difference (RD) for TLR of $-1.16 \%$ at 1 year [ $95 \%$ confidence interval (CI): $-1.96 \%$ to $-0.35 \%$ ] and of $-1.79 \%$ at 3 years (95\% CI: $-2.75 \%$ to $-0.84 \%$ ) in favour of newer-generation DES. To apply the equivalence testing to these findings, we sought information on the margins in previous trials conducted on this topic; Stone et al. [2] adopted the endpoint of TLR in their trial comparing everolimus-eluting vs paclitaxel-eluting stents and employed a margin of $\pm 2.9 \%$ expressed as RD. Any difference within the limit of $2.9 \%$ in TLR rates can therefore be assumed to identify an equivalence interval; other randomized studies in this area have generally adopted wider margins (between $3 \%$ and $4 \%$ ). Hence, our equivalence test [5] was designed to combine the values of RD found by Stefanini et al. [1] with the margins adopted by Stone et al. [2].

\section{Results}

Our results, based on the end-point of TLR, are summarized in Figure 1. The Forest plot clearly shows that, in women, there is an equivalent effectiveness between newer-generation and early-generation DES.

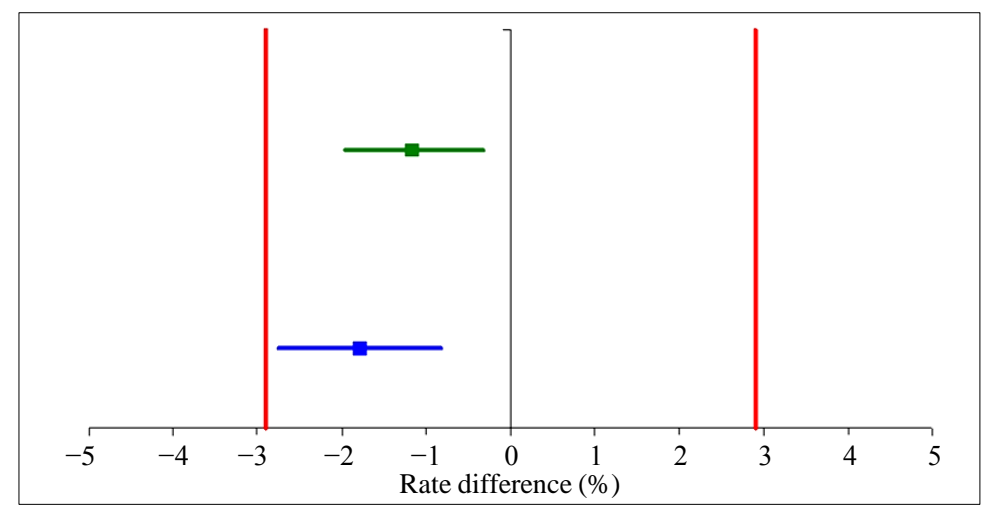

Figure 1. Forest plot and test of equivalence: rates of TLR in women treated with newer-generation DES or early-generation DES. The test is based on the area comprised between the two red vertical lines, that reflect the pre-determined equivalence margins (around the value of rate difference = $0 \% \pm 2.9 \%$ ). The horizontal bars indicate the two-sided 95\% CI for the RD (solid square) between newer-generation DES and early-generation DES. On the $\mathrm{y}$-axis shows, the two data-sets for RD are presented according to the follow-up of 1 year (in green) and 3 years (in blue). The criterion for demonstrating equivalence is when both extremes of the $95 \%$ CI remain within the two vertical red lines. The graph shows that this criterion is met in both cases. This analysis is based on the same primary data as those reported by Stefanini et al. [1]. Abbreviations: DES, drug-eluting stents; CI, confidence interval; RD, rate difference, TLR, target lesion revascularization. 


\section{Discussion}

Since the interpretation made by Stefanini et al. [1] of their results was that the newer-generation of DES is more effective than the early-generation one, and this issue deserves a close scrutiny. As pointed out by Ahn et al. [5], when a specific data set indicates, at the same time, equivalence and superiority, the interpretation is controversial, and two different hypotheses can be proposed. First, equivalence margins were too wide, and so superiority should prevail in the interpretation. Second, the margins were reasonable, so the conclusions should favour equivalence. In this specific case, we think that priority should be given to equivalence rather than to superiority.

\section{Conflict of interests}

None declared.

\section{Acknowledgements}

The authors have carried out this study in the context of their activity at the above mentioned institution; ESTAV Centro belongs to the Italian national health system.

\section{References}

[1] Stefanini, G.G., Baber, U., Windecker, S., Morice, M.C., Sartori, S., Leon, M.B., Stone, G.W., Serruys, P.W., Wijns, W., Weisz, G., Camenzind, E., Steg, P.G., Smits, P.C., Kandzari, D., Von Birgelen, C., Galatius, S., Jeger, R.V., Kimura, T., Mikhail, G., Itchhaporia, D., Mehta, L., Ortega, R., Kim, H.S., Valgimigli, M., Kastrati, A., Chieffo, A. and Mehran, R. (2013) Safety and Efficacy of Drug-Eluting Stents in Women: A Patient-Level Pooled Analysis of Randomised Trials. Lancet, 382, 1879-1888.

[2] Stone, G.W., Rizvi, A., Newman, W., Mastali, K., Wang, J.C., Caputo, R., Doostzadeh, J., Cao, S., Simonton, C.A., Sudhir, K., Lansky, A.J., Cutlip, D.E. and Kereiakes, D.J. (2010) Everolimus-Eluting versus Paclitaxel-Eluting Stents in Coronary Artery Disease. The New England Journal of Medicine, 362, 1663-1674. http://dx.doi.org/10.1056/NEJMoa0910496

[3] Messori, A., Fadda, V., Maratea, D. and Trippoli, S. (2014) Outcomes with Short-Term versus Long-Term Antiplatelet Dual Therapy after Drug-Eluting Stenting: Quantifying the Equivalence Margins. International Journal of Cardiology, 172, 469-470. http://dx.doi.org/10.1016/j.ijcard.2013.12.228

[4] Messori, A., Maratea, D., Fadda, V. and Trippoli, S. (2014) Risk of Intracranial Haemorrhage in Patients with Atrial Fibrillation Treated with Novel Oral Anticoagulants: Testing the Equivalence Margins between Dabigratran, Rivaroxaban and Apixaban. European Journal of Clinical Pharmacology, 70, 505-506.

[5] Ahn, S., Park, S.H. and Lee, K.H. (2013) How to Demonstrate Similarity by Using Non-Inferiority and Equivalence Statistical Testing in Radiology Research. Radiology, 267, 328-338. http://dx.doi.org/10.1148/radiol.12120725 